\title{
New nanotechnologies for Energy saving and Resiliency of the Built Environment ${ }^{\dagger}$
}

\author{
Umberto Berardi ${ }^{1}$ \\ 1 Ryerson University, Toronto, Ontario, Canada \\ * Correspondence: uberardi@ ryerson.ca; \\ $\uparrow$ Presented at Materials Chemistry and Physics (Materials Chemistry 2020) - International e-Conference
}

Received: 16.09.2020; Revised: 20.09.2020; Accepted: 24.09.2020; Published: 27.09.2020

\begin{abstract}
The focus of this paper deals with innovative material and construction systems that incorporate nanotechnologies for improving their energy-saving performance. Recent developments in the world of phase change materials, specifically on organic PCMs, such as paraffin and bio-PCM aerogel, are presented; laboratory works are presented together with pilot projects in Toronto, where PCM-based system have been incorporated in high-performing buildings. Then, the paper shows recent advancements in super-insulating materials, specifically focusing on aerogel-enhanced blankets and panels, which have been developed at the BeTOP laboratory of the Ryerson University in Toronto, Ontario. Finally, the paper explores the potentialities of including innovative thermochromic coatings at the urban scale and shows the mutual benefits between buildings and communities that could be obtained through the adoption of previously mentioned nanotechnologies. The goal is to describe a pathway towards more sustainable and resilient communities. Using Toronto as a test case, the paper aims to comprehensively show that nanotechnologies offer a paradigm shift at the different scales of the built environment.
\end{abstract}

Keywords: nanotechnologies; energy efficiency; high-performance buildings.

(C) 2020 by the authors. This article is an open-access article distributed under the terms and conditions of the Creative Commons Attribution (CC BY) license (https://creativecommons.org/licenses/by/4.0/).

\section{Funding}

This research was funded by several grants, including a Canada Foundation for Innovation JELF, an NSERC Discovery Grant, and the Early Research Award from the Ontario MRI

\section{Acknowledgments}

The support of all the previous and present researchers working at the BeTOP Lab directed by dr. Berardi is highly acknowledged. Overall, this paper would not be possible without their passion and commitment.

\section{Conflicts of Interest}

The author declares no conflict of interest. 